$$
\text { Bi-monthly Report }
$$

for Period February 1, 1977 - March 31, 1977

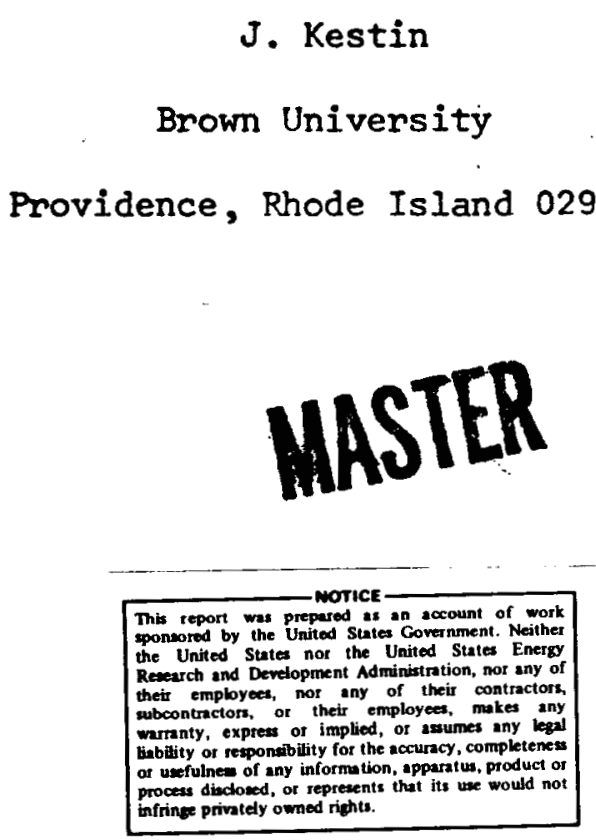

April 1977

Prepared for

THE U.S. ENERGY RESEARCH AND DEVELOPMENT ADMINISTRATION UNDER CONTRACT NO. EY-76-S-02-4051.000 


\section{DISCLAIMER}

This report was prepared as an account of work sponsored by an agency of the United States Government. Neither the United States Government nor any agency Thereof, nor any of their employees, makes any warranty, express or implied, or assumes any legal liability or responsibility for the accuracy, completeness, or usefulness of any information, apparatus, product, or process disclosed, or represents that its use would not infringe privately owned rights. Reference herein to any specific commercial product, process, or service by trade name, trademark, manufacturer, or otherwise does not necessarily constitute or imply its endorsement, recommendation, or favoring by the United States Government or any agency thereof. The views and opinions of authors expressed herein do not necessarily state or reflect those of the United States Government or any agency thereof. 


\section{DISCLAIMER}

Portions of this document may be illegible in electronic image products. Images are produced from the best available original document. 
During the reporting period, the Brown University geothermal energy group performed the following activities:

1. A review of the thermodynamic property correlations for isobutane has been and continues to be performed. Original measurements have been collected from the literature, and the equations of state proposed by K. E. Starling ${ }^{(1)}$ and P. T. Eubank et al ${ }^{(2)}$ have been used as correlating equations for the compressed liquid, saturation, and superheated vapor states, including the near-critical and supercritical region. These two equations are in agreement with each other and with experimental data for saturation properties. There are, however, discrepancies for both the compressed-liquid and supercritical regimes: The equation of Starling shows departures of $10-12 \%$ from the measurements of Beattie, et al ${ }^{(3)}$ at the highest densities, while that of Eubank, et al $^{(3)}$ reproduces the measurements to about 18 . Figures 1 and 2 illustrate these comparisons.

This work will be pursued and the comparisons made on the enthalpy over the same range of states.

2. Two members of the group (J. Kestin and H. E. Khalifa) attended a meeting at ERDA, Washington, DC on March 18, 1977 on the subject of extraction technology. H. E. Khalifa prepared the minutes of the conference. A copy of these minutes is attached to this report as an appendix.

(I) K. E. Starling, Fluid Thermodynamic Properties for Light Petroleum Systems, Gulf Publishing Co., Houston, 1973, p. 194.

(2) T. R. Das, C. 0. Reed, Jr. and P. T. Eubank, Chemical E Engineering Data, 18 (1973) 253 .

(3) J. A. Beattie, S. Marple, Jr. and D. G. Edwards, Chem. Phys., 18 (1950). 127; J. A. Beattie, D. G. Edwards and S. Marple, Jr., J. Chem. Phys. 17 (1949) 576. 
3. A search and screen committee has been established (Chaiman, R. DiPippo) to seek a person with expertise in two-phase flow to join the Brown group for one year, 1977-1978, subject to the renewal of the present grant. Letters and a job description have been sent to a variety of potential sources for candidates.

4. The minutes of the Fourth Meeting of the CATMECs were completed and distributed to the participants and other interested parties.

5. Extensive discussions and negotiations have taken place between Brown University and General Electric relative to promoting a much closer working relationship between these two groups. It is the intention to establish General Electric as a subcontractor to Brown University for the next phase of the project.

6. Preparations have been made, the agenda drawn up and the Geothermal Energy Sourcebook outline revised for the Fifth Meeting of the CATMECs to be held at Terra Tek, Inc. on the campus of the University of Utah, Salt Lake City on April 12-13, 1977. A field trip to the Roosevelt Hot Springs KGRA has also been planned for April 14, 1977.

7. The weekly seminar series has continued with the following topics under discussion:

2/1/77 Mechanics of Nucleation and Supersaturation, Part 1 (R. A. Dobbins)

2/8/77 Mechanics of Nucleation and Supersaturation, Part 2 (R. A. Dobbins)

2/15/77 Mechanics of Nucleation and Supersaturation, Part 3 (R. A. Dobbins)

$2 / 22 / 77$ Effects of Liquid Droplets on Expansion in Turbines 
3/1/77 Regimes of Two-Phase Flow in Vertical Pipes ( $W$. Leidenfrost)

$3 / 8 / 77$ Comparisons of formulations of the properties

of isobutane

(S. B. Katzovicz)

3/15/77 Production Wellflow Analysis

(H. E. Khalifa)

3/22/77 Review of ERDA, Washington Meeting on Production

Wellflow

(H. E. Khalifa)

Design Aspects of Freon/Hydrocarbon Turbines

(R. DiPippo)

3/29/77 General Discussions:

Project objectives and directions

Plans for Salt Lake City Meeting

Geothermal well pumping.

In addition, R. DiPippo presented two lectures at Southeastern

Massachusetts University under the sponsorship of the Student Chapter of the ASME:

2/16/77 Geothermal Energy, Part I: An Overview of Present Applications and Future Potential

2/28/77 Geothermal Energy, Part II: The Production of Electricity from Hydrothermal Resources.

8. J. Kestin, the principal investigator has devoted $25 \%$ of his time to the project in both February and March. The staff includes:

- Dr. H. E. Khalifa, Assistant Professor of Engineering (Research)

- Dr. R. DiPippo, Visiting Professor of Engineering (Research)

- Dr. P. F. Maeder, Professor of Engineering and Vice President for Finances $\varepsilon$ Operations (consultant)

- S. B. Katzovich, Research Assistant. 
SUPERCRITICAL REGION

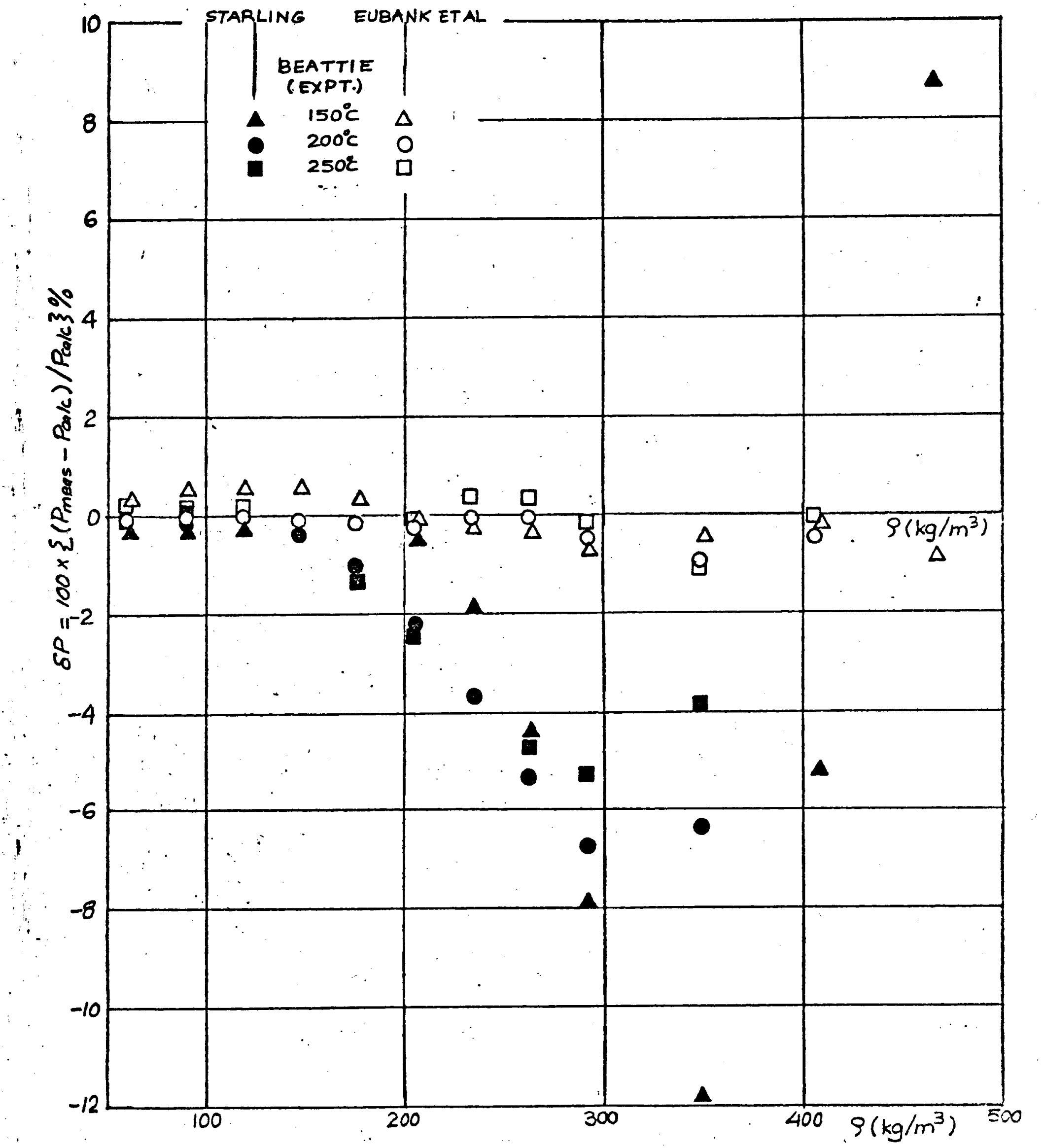

Fig. 1. Comparison of Starling and Eubank, et al equations of state for isobutane with measurements of Beattie, et al: Supercritical region. 
CRITICAL REGION

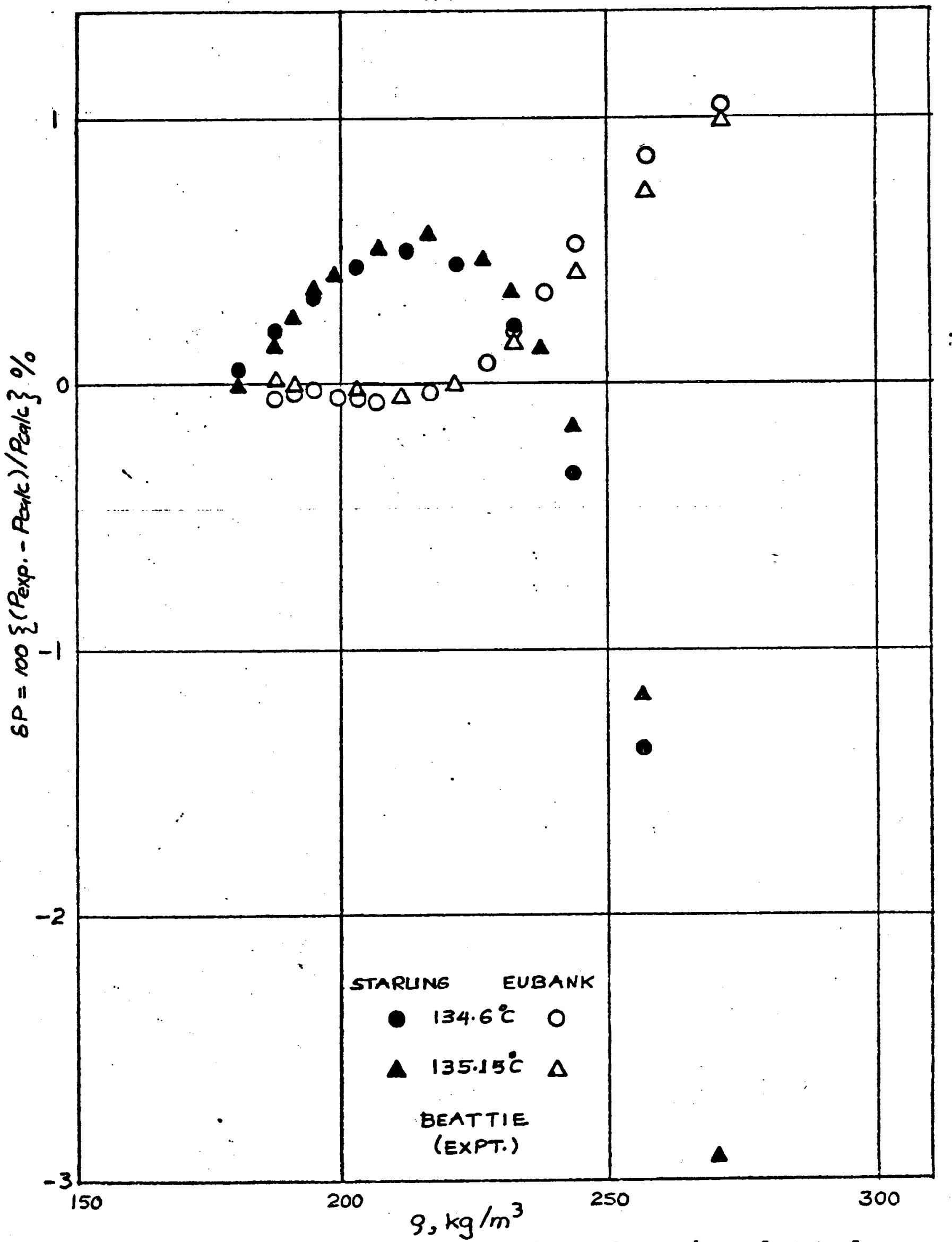

Fig. 2. Comparison of Starling and Eubank, et al equations of state for isobutane with measurements of Beattie, et al: Critical region. 
APPENDIX 
Brown University

Center for the Analysis of

Thermal/Mechanical Energy

Concepts

March 24, 1977

\author{
Extraction Technology Meeting \\ Washington, D.C. \\ March 18, 1977 \\ Minutes prepared by \\ H. Ezzat Khalifa \\ Division of Engineering \\ Brown University \\ Providence, RI 02912
}

Energy Research and Development Administration

Purpose :

1. Define Extraction Technology and Economic Issues

2. Review State of the Art and the Status of Current Research Resolve Issues where possible.

3. Establish a Basis for Current and Planned RED-Activities

4. Identify Requirements for New Research.

5. Document Expert Opinion.

\title{
Agenda :
}

c. B. McFarland distributed an agenda for the meeting. However, owing to the informal nature of the meeting, the items on the agenda were not discussed in the order given. A copy of the original agenda is attached as Appendix A. 
List of Participants

\author{
Clifton Carwile \\ ERDA - DGE \\ 20 Massachusetts Ave., NW \\ Washington, DC 20545 \\ Glenn Coury \\ Coury $\&$ Associates \\ 7400 W. 14th Ave., \#2 \\ Lakewood, CO 80214 \\ Abraham Dukler \\ University of Houston \\ Houston, TX \\ David Elliott \\ Jet Propulsion Laboratory \\ 4800 Oak Grove Drive \\ Pasadena, CA 91103 \\ Richard Fuller \\ Sperry Research Center \\ 100 North Road \\ Sudbury, MA 01776 \\ John Halat \\ Sperry Vickers \\ 5353 Highland Drive \\ Jackson, MS \\ Joseph Kestin \\ Brown University \\ Box D \\ Providence, RI 02912 \\ H. Ezzat Khalifa \\ Brown University \\ Box D \\ Providence, RI 02912 \\ James Kuwada \\ Rogers Engineering Co. \\ 111 Pine Street \\ San Francisco, CA 94111 \\ Hugh Matthews \\ Sperry Research Center \\ 100 North Road \\ Sudbury, MA 01776
}

Warren McBee

Sperry Research Center

100 North Road

Sudbury, MA 01776

Clifton MeFarland

ERDA - DGE

20 Massachusetts Ave., $\mathrm{NW}$

Washington, DC 20545

Kenneth Nichols

Barber-Nichols Engineering

6325 W. 55th Ave.

Arvada, CO 80002

William Ross

Denver Research Institute

Denver, CO 80208

Ronald Schroeder

Lawrence Berkeley Laboratory

Berkeley, CA 94720

John Walker

ERDA - DGE

20 Massachusetts Ave., NW

Washington, DC 20545 
Minutes

1. C. B. McFarland opened the meeting by stating the motivation for the meeting and its purpose. He also outlined the pregram of the day.

2. D. G. Elliott summarized his findings in relation to well flow and pumping in three statements that created considerable discussions:

1. No-slip model is "pretty good"

2. Usefulness of well flow calculation is doubtful

3. Wellhead total availability is as high or better in self-flowing wells as in pumped wells.

Elliott was intermupted several times for extensive discussions by the other participants. It was argued that the no-slip model is quite inaccurate in modelling geothermal well flow. Elliott mentioned that he applied this simple model to three wells with reasonable success and argued that one needs data from existing wells anyhow and a more sophisticated two-phase model is not needed. It was pointed out by Dukler that realistic models are still needed to cope with the various situations such as inclined wells. The basis upon which Elliott chose his friction factor was also debated. It was mentioned that Elliott's need for an assumed heat transfer coefficient in some of his calculations may be a consequence of the faulty twophase model rather than nonadiabatic considerations. It was also argued that the reason Elliott was able to obtain satisfactory results under some conditions may lie in the smallness of the two-phase pressure drop in comparison with the drawdown so that the crudeness of the two-phase model will have an attenuated effect on the final results.

Elliott's third statement also generated a lively discussion although it was generally accepted that the total rather than the specific availability at the wellhead is the right criterion. Some argued that the problems of well production should always be analyzed with an eye on economics. The quality of the fluid at the wellhead may have little to do with thermodynamic criteria but can drastically affect the design and cost of surface equipment. It was also stated that it is important to study the various components in a system before studying the system as a whole; a realistic two-phase flow model will help in the optimum selection of the casing program as well as the type, size, and elevation of the pump, if any. It was mentioned that data from old wells could be unreliable due to the possible existence of a plug somewhere in the well.

Kuwada brought up the subject of the brine gas content and the influence it has on scale deposition, well production, and equipment design. He stated that the well head pressure should be high enough to prevent evolution of dissolved gas in the formation or in the well pipe. It was agreed that the scaling problem and the resulting plugging is one of the most serious problems in wells. It was also agreed that scaling avoidance, not increased well production, may well be the controlling factor in settling the issue of whether to pump or not to pump. Wells can be reamed frequently to get rid of the scale deposits as is done at Cerro Prietto. The subject of brine chemical treatment in order to inhibit the formation of scale was also briefly discussed. 
3. A. E. Dukler discussed the subject of two-phase flow modelling. He emphasized the following aspects:

I. Flow regimes

- vertical adiabatic non-flashing flows

- effect of deviations from verticality on some regimes

- effect of heat transfer between phases

- characterizations of transition from one regime to another.

II. Holdup (volume fraction of liquid)

- Friction, dependence on flow regime

- In vertical pipes, fog flow is almost impossible to obtain without heating the walls. The prevailing regime will be the annular flow instead

- In annular flow the friction is due mainly to momentum exchange between the core drops and the annular film and the waviness of the interface.

III. Measurements

- Gamma-ray densitimeter

- Capacitance method

- Magnetic inductance method.

The question of the quantitative value of these studies in geothermal well flow was raised. It was stated that the actual friction factors on the basis of these studies can be 3-6 times greater than in the homogeneous model. It was also mentioned that slug or chumn regimes will probably prevail in geothermal wells. Dukler gave an example of how to define the transition from one regime to another on the basis of the stability of the various regimes and the influence of the holdup. He added that the initial effort was directed towards developing the two-phase flow model and checking it with respect to the wells at East Mesa. Kuwada cautioned against possible errors in measuring mass flow rates by means of orifice meters caused by flashing at the orifice plate.

4. G. E. Coury pointed out to the sparsity and lack of reliability of the existing data on geothermal wells. He said that he does not want to try his computer program on these data until he checks the conditions under which they were obtained. In answer to a question about the possible errors in the various correlation schemes applied to geothermal well flow, Coury said that some correlations are in error by orders of magnitude.

Coury summarized the activities of Coury and Associates:

- brine chemistry

- dissolved gas and the effect of its release on scaling

- two-phase flow calculations.

He mentioned that although his two-phase program will yield the holdup at any point in the well together with the friction losses, it will be difficult to carry out heat transfer calculations. It was mentioned that the controlling factor in evaluating the heat losses along the well will be the poor thermal conductivity of the rock rather than the convective heat transfer coefficients inside the pipe. McFarland questioned whether small amounts of heat loss may have a strong influence on the pressure gradient in the well nipe. Dukler's previous calculations had indicated that possibility. MeFarland referred to a report by Dukler which has indicated that possibility. 
Coury also mentioned that he intends to compare the results of the other twophase models to his own as well as to actual data from geothermal wells. He spoke briefly about the measuring probe being developed at Coury and Associates.

5. K. Nichols discussed his company's activities in testing the Sperry downhole pump at the Heber site. He commented that the power generation system and the brine production system should always be treated as one whole. It was mentioned that the cost of the wells and downhole equipment are roughtly the same.

Fuller asked whether the conclusions of Elliott will be adopted in the Geothermal Handbook. Kestin and McFarland stated that Elliott's analysis is just a "first iterate" and that the purpose of this meeting is to clarify the matter further. Also it was indicated that the handbook will present the methodology and, where possible, the relevant data for comparative analysis rather than a set of specific conclusions.

Nichols continued the description of the hardware (turbine-pump). He showed photographs of the disassembled turbine-pump unit. The pump impeller is of the screw type (mixed-flow) of about 4" diameter for a well bore of 8 5/8". The turbine is a velocity compounded Curtis wheel. The combination runs at speeds of $15000-17000 \mathrm{rpm}$ and was designed for a flow rate of $1000 \mathrm{gpm}$ and a total pressure rise of $200 \mathrm{psi}$. Nichols stated that the suction specific speed at the design point was 8000 (gpm units) in order to avoid cavitation. The pump efficiency at the design point is about $80 \%$ whereas the turbine efficiency at its best efficiency point is $50-55 \%$. The system was tested in the laboratory. The pump was also tested at the Heber site. Nichols mentioned that the pump casing was made of monel metal while the rotor was made of hardened stainless steel; the bearings were made of ceramic and were lubricated by water. The bearings failed after 28 days of operation in the well. It was observed that the flow contained an appreciable amount of sand. The amount of sand increased when the flow rate was increased, but the sand concentration dropped after operating for some time under steady conditions. Nichols noted that the well productivity changed quite considerably with time. He blamed this on calcite precipitation.

McBee stated that the problems associated with pumps are generally related to operation and maintenance rather than efficiency. He said that one of the problems they encountered was the design of the falling film heat exchanger (boiler). A switch to an organic working fluid for the driving turbine was found necessary in order to operate in the supercritical region.

Nichols summarized as follows:

a - It is possible to operate the sperry pump for extended periods of time under actual well conditions;

b - The behavior of the pump in the well agreed with the performance characteristics obtained in the laboratory;

c - A great number of problems were discovered in the well testing, the knowledge of which will help improve the design of the prototype.

d - Extrapolating the experience of the oil and gas industry can be dangerous;

e - Downhole instruments are badly needed. 
Nichols also mentioned that the design of the pump is limited by the small diameter of the bore; slower and more reliable pumps can be designed if larger bores are feasible.

Matthews mentioned that the use of an organic working fluid can improve the performance of the system. The temperature drop per 100 psi pressure rise in the pump can be decreased to $3^{\circ} \mathrm{F}$ for a wellhead temperature of $350^{\circ} \mathrm{F}$ rather than $6^{\circ} \mathrm{F}$ for steam.

Kuwada commented that regardless of the method of production (self-flowing or pumped) the maximum flow rate is limited by the reservoir. He agreed with McBee that there is a growing need for downhole pumps.

McFarland summarized the discussions and emphasized that the Geothermal Handbook will go through several iterations before putting it in a final form. 


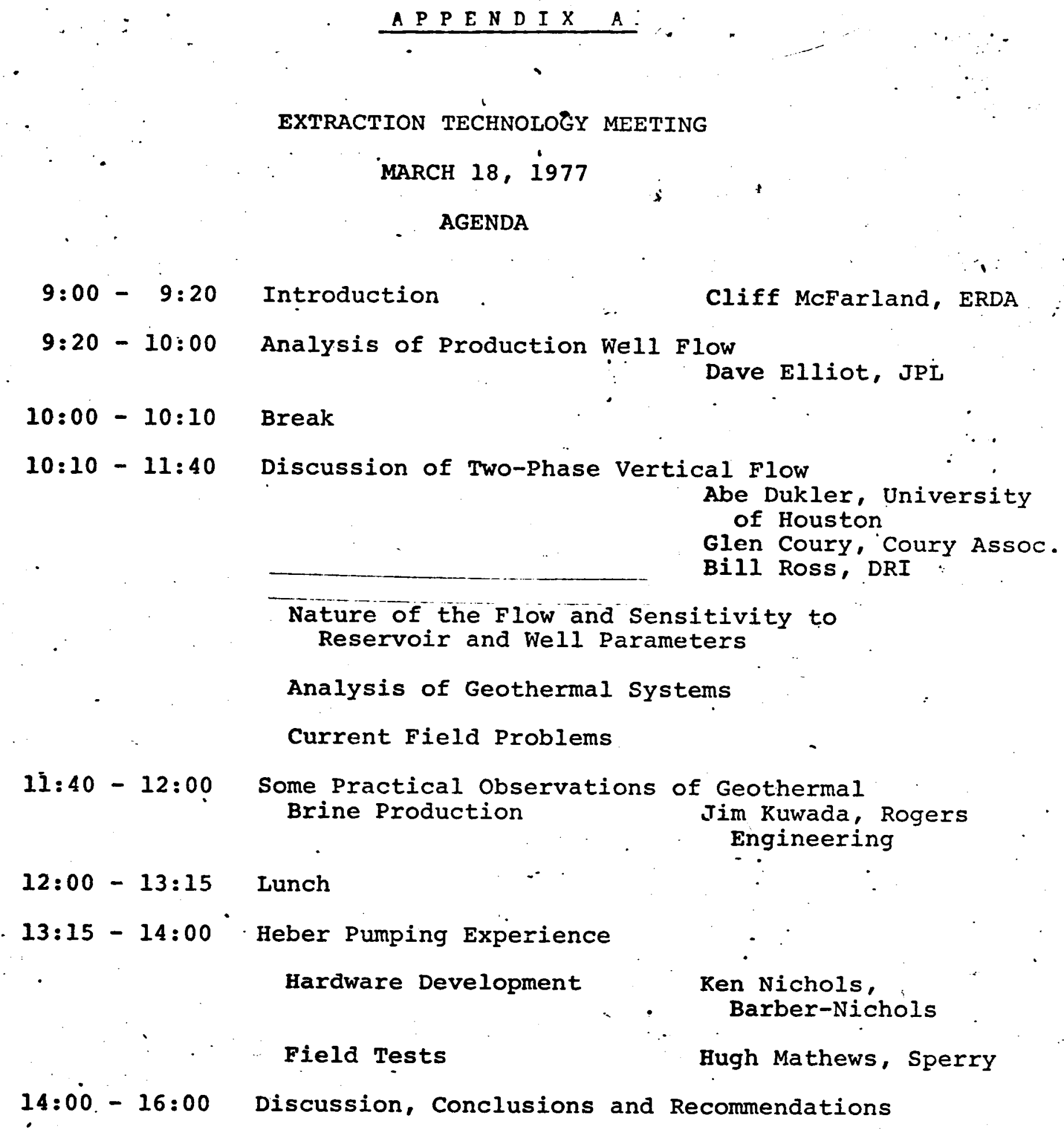

